\title{
Analyzing the Application of Two Main Microcontrollers in Engineering Education - A Case Study of three IEEE Conferences Focusing on Education
}

\author{
Arthur James Swart* \\ Central University of Technology, Bloemfontein, 9301, South Africa
}

\begin{tabular}{l} 
A R T I C L E I N F O \\
\hline Article history: \\
Received: 01 March, 2021 \\
Accepted: 10 May, 2021 \\
Online: 15 June, 2021
\end{tabular}

Keywords:

Arduino

Raspberry Pi

EDUCON

FIE

TALE

A B S T R A C T
Microcontrollers have revolutionized the field of Engineering Education. Their popularity
and cost-effectiveness have opened a large door of activity for innovative projects at both
the undergraduate and graduate levels. The purpose of this article is to review this activity
in terms of where two of these microcontrollers have been used in Engineering Education so
as to recommend further possible applications. Focus is limited to papers presented at three
IEEE-based conferences over the past 10 years that mentioned the Arduino or Raspberry Pi.
Documentary analysis is thus used where the abstracts of the conference papers were
reviewed. Results indicate that EDUCON dominated the field of microcontroller education
from 2013 to 2016, while the last three years have seen more papers dedicated to this topic
being presented at the FIE series of conferences. A total of nine papers relating to
microcontroller education has also been presented at TALE between 2012 and 2019 . The
main application of these microcontrollers has been in the field of Robotics, with general
electronics and design-based learning following suit. At least 11 conference papers focusing
on the use of these microcontrollers at school level were found. Overall, the Arduino
outranks the Raspberry Pi by almost $4: 1$, with the most cited papers relating to Robotics
education, to helping students at home to complete science and technology experiments and
to programming. Further applications can extend to energy monitoring and academic
development workshops.

business intelligence, quantitative stock trading and social media exploration [1]. This has been extended to many different applications and fields of study, including Education. Identified trends in a specific field can be used to create awareness of what type of research has dominated a given topic over time and in formulating further recommendations with regard to that topic. For example, consider research on the trends relating to microcontroller education. A study noted the widespread dissemination of the Do-It-Yourself (DIY) culture and how modern-day microcontrollers have helped to fuel this culture [2]. Based on the trends identified in that study, a recommendation was made to use a multi-platform method using 8-bit microcontrollers and embedded $\mathrm{C}$ programming to maintain the effectiveness of microcontroller education. However, that study did not indicate how the number of publications relating to microcontroller education had increased over time, neither were the specific applications listed. This would help to identify further opportunities for the future application of microcontroller education.

"Corresponding Author: Arthur James Swart, Email: drjamesswart@gmail.com 
Previous research has contrasted conference papers, journal articles and student dissertations to obtain bibliometric data [3-5]. However, the novelty of this study lies in its purpose, which is to contrast papers from three international IEEE conferences with regard to the application of microcontrollers in Engineering Education, so as to identify possible further applications. The use of citation analysis in this study is not for purposes of bibliometric analysis, but rather to determine which applications have attracted the most interest from fellow researchers around the globe. The article starts with a discussion on the rise of microcontrollers in Education. The context is then given along with the methodology. Results and conclusions follow at the end.

\section{The rise of microcontrollers in Education}

Microcontrollers were first considered at Intel in 1969 when a Japanese company approached Intel to build some integrated circuits for calculators [6]. Their history thus spans half a century, yet their impact has been extraordinary over the past two decades. They have indeed revolutionized electronic data acquisition systems [7], which is one of their primary applications.

Microcontrollers are used in many applications that require data acquisition, including industrial automation, control, measuring and consumer electronics [8]. They can be used in everything from relatively simple systems such as washing machines and vacuum cleaners, to much more advanced systems such as cars and robots [9]. In fact, they have become ubiquitous in our daily lives [10]. Its widespread adoption has necessitated changes to educational curricula, as institutions of higher learning move to make their programmes more relevant to the everchanging technological landscape. These institutions seek to gain a competitive edge in the market of student recruitment, as they claim that their graduates will be better prepared to meet the demands of industry in the Fourth Industrial Revolution. Indeed, this revolution has been called "disruptive", as many changes have followed in its wake [11]. These changes led to the enhancement of new competence requirements (often termed "graduate attributes") and foster adjustments and the updating of qualifications. It also leads to the emergence and extinction of qualifications.

These changes are also evident in many school programmes, as governments seek to strengthen Science, Technology, Engineering and Mathematics (STEM) education among its youth. For example, in South Africa, President Cyril Ramaphosa has indicated in 2019 that government will introduce Coding and Robotics in primary schools (first years of schooling termed Grades R to 3) with a plan to implement it fully by 2022 . This is one of the steps taken by government to improve education in the country. Indeed, in many western countries, Robotics is becoming increasingly common in primary and secondary education, both as a specific discipline and a tool to make STEM subjects more appealing to children [12].

\section{Context of this study}

The context of this study is limited to conference papers presented at three IEEE conferences that focused on Engineering Education. These conferences are [13]:
- EDUCON: This Global Engineering Education Conference provides a forum for academic, research and industrial collaboration on global Engineering Education. It is the flagship conference of the IEEE Education Society for Europe, the Middle East and North Africa (IEEE Region 8).

- FIE: Frontiers in Education has become the premiere conference for innovative curricula, Engineering Education and research excellence. This conference is usually held in various locations around the United States (IEEE Regions 16) and, occasionally, in international venues.

- TALE: This International Conference on Engineering, Technology and Education is the IEEE Education Society's flagship in the Asia-Pacific region (IEEE Region 10). It caters for researchers and practitioners with an interest in engineering, technology, and integrated STEM education, as well as those interested in the innovative use of digital technologies for learning, teaching, and assessment in any discipline.

The reason for focusing only on these conferences is the fact that they are rated by Microsoft Academic [14] under the top ten Engineering Education conferences in the world, and they focus on all fields of Engineering. Many of the top ten conferences on the Microsoft Academic list are field specific, such as Instrumentation, Cybernetics, Data Mining, Computer Science and Collaborative Learning.

The topic of interest is limited to the use of two microcontrollers, namely the Arduino and Raspberry Pi. The main reason for this is due to the dominance of conference papers on these two microcontrollers at the three conferences. Figure 1 highlights the total number of conference papers per year that included the word "microcontroller" for these three conferences, as found on the IEEE Xplore website.

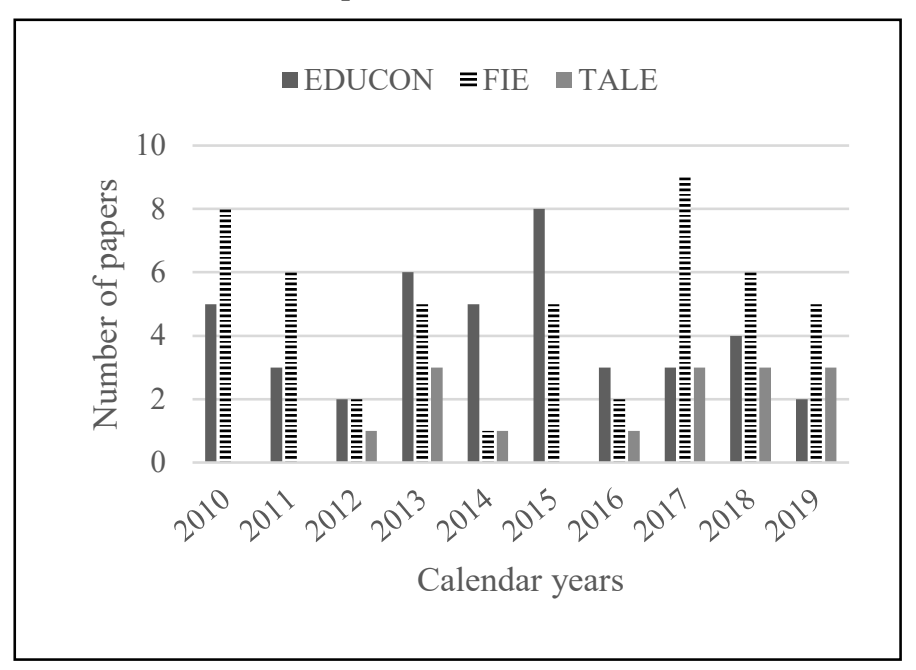

Figure 1: Conference papers using the word "microcontroller" from 2010 to 2019

More than $50 \%$ of these conference papers were related to the Arduino and Raspberry Pi. A secondary reason relates to the availability of communities of developers in which the participants share codes and experiences in projects relating to these platforms [14], which would make them easier to implement in Engineering Education. 
It is noteworthy that EDUCON dominated the period of 2013 to 2016, while FIE dominated the last three years relating to the number of papers presented that mentioned the words "Arduino" and "Raspberry Pi". This fluctuation can negate forecasting in terms of which conference will dominate microcontroller education over the coming years. However, this "perceived" competition does bode well for the growth of microcontroller Education, especially within other fields of study or in other applications.

\section{Methodology used}

Documentary analysis were used where the abstracts of papers from the three conferences were reviewed. Documentary analysis is an important source of information, because it is non-relative, meaning that the information found in documents will remain the same over time [15]. These abstracts are retrieved from the IEEE Xplore database by limiting the search to three IEEE-based conferences, and by then searching within the results. For example, EDUCON is inserted into the search bar available on the home page. Conferences are then applied on the next page. Search within results is then used to first search for the word "Arduino" and then for the words "Raspberry Pi". The same procedure is then repeated for FIE and TALE. The search is limited to the time period of 2010 to 2019 , as many conferences were impacted negatively in 2020 due to the global COVID-19 pandemic.

Abstracts are downloaded into a MS EXCEL sheet, where they are reviewed in terms of the field of application, number of authors, level of education and number of citations obtained since the publication. The citations can help to evaluate the impact of the publications [16], and also point to fields of application that are important to other researchers in Engineering Education. A large number of co-authors may indicate that more cross-disciplinary research is taking place. Within science, many studies have shown that papers with more co-authors tend to attract more citations [17].

\section{Results}

\subsection{EDUCON results}

Figure 2 contrasts the level of education where the microcontrollers have been applied. Arduino has dominated the discourse on the use of microcontrollers in Engineering Education as presented at EDUCON. A total of 15 papers were dedicated to it, with eight applied in Higher Education. It is encouraging to see that it has also been applied to STEM education at school level, where three papers were found in this regard. The Raspberry Pi has only been reported on in five papers relating to Higher Education. The generic column indicates that three papers reported on different levels of education where the Arduino has been implemented. Figure 3 indicates the various applications for the two microcontrollers that were presented since 2010 at EDUCON.

The main application relates to Robotics when considering the Arduino in Figure 3. This is not surprising, as Robotics research has increased at a rapid pace around the globe. More industries are searching for graduates with Robotics experience, and institutions of Higher Education are introducing new curriculums that include Robotics education. In fact, this is even being introduced at school level in South Africa, as mentioned earlier.
Electronics (A/D) feature second on the list of applications. Both basic analogue and digital electronics are covered in this number (three), indicating that the Arduino microcontroller has also been used to convey fundamental principles to Engineering students. Some principles may seem to be abstract to certain students. Seeing the "theory" in "practice", or in action, does indeed help students to grasp and retain key principles. This may also be applied to the application of design (two papers dedicated to this), where students need to understand various concepts that need to be synthesized to obtain a working model.

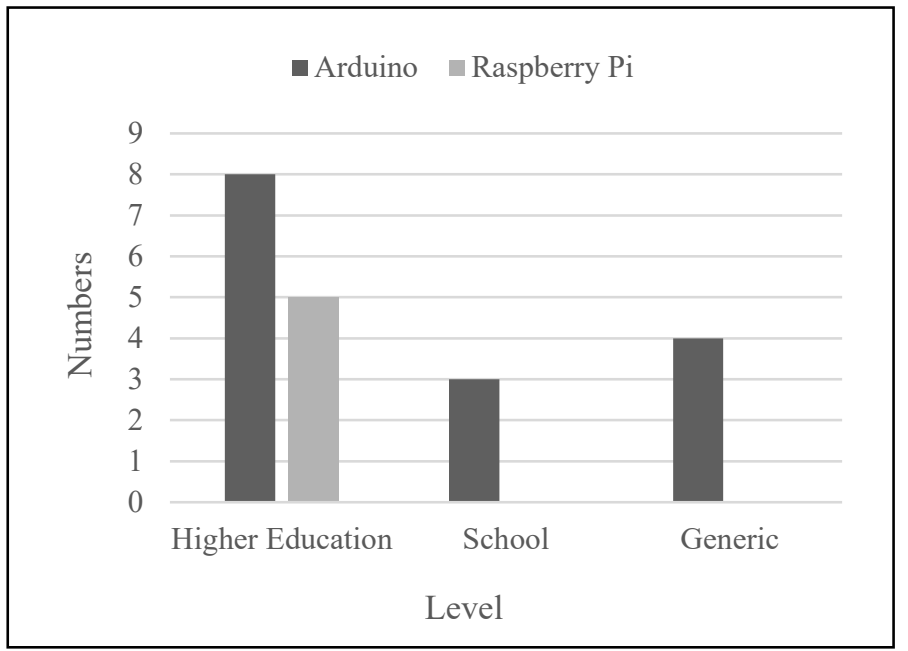

Figure 2: Level of education noted for papers presented at EDUCON

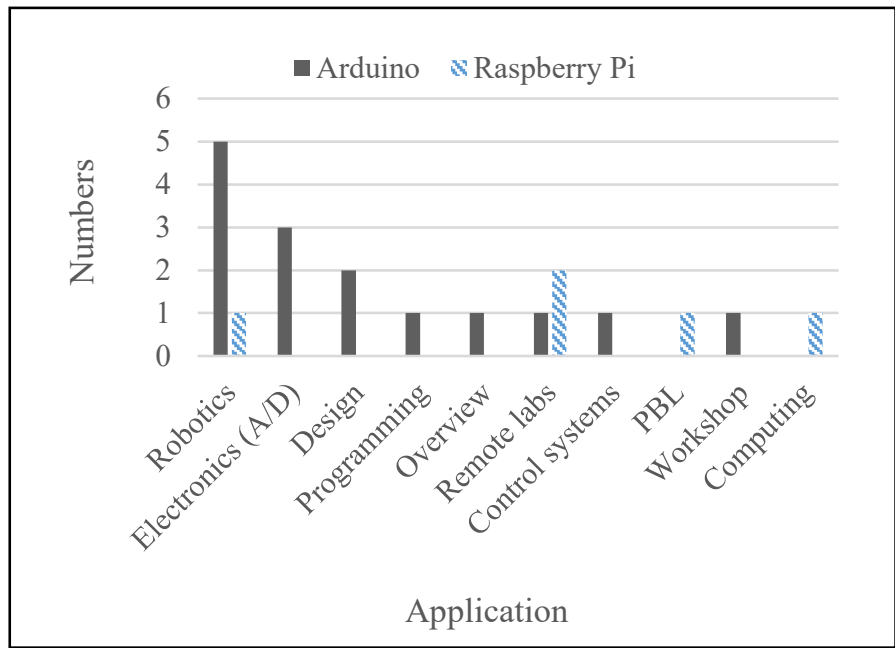

Figure 3: Applications discerned in EDUCON papers from 2010 onwards

The application "Design" covers the creation of an electronic circuit to fulfill specific requirements. "Programming" involves learning a new computer language, such as $\mathrm{C}++$, while "Remote labs" involve online work were students can access an online remote laboratory from their place of residence to complete practical experiments. "Control systems" or "Control" require students to control electrical or mechanical equipment by using a microcontroller, while "PBL" (problem-based learning) requires students to make use of microcontrollers to solve an engineeringrelated problem. The "Workshop" application indicates a short course in which academics or students are trained in the basic use of a microcontroller, while "Computing" calls on students to 
implement a microcontroller to perform mathematical or procedural tasks. The rest of the applications featured in only one paper each, with the dominant Raspberry Pi application being remote laboratories. This is expected, as the Raspberry Pi is a lowcost single-board computer that can function as a web server.

Figure 4 shows the number of authors for the 15 conference papers relating to Arduino as presented at EDUCON over the past ten years, along with their citation count. Figure 5 provides this same analysis for the Raspberry Pi.

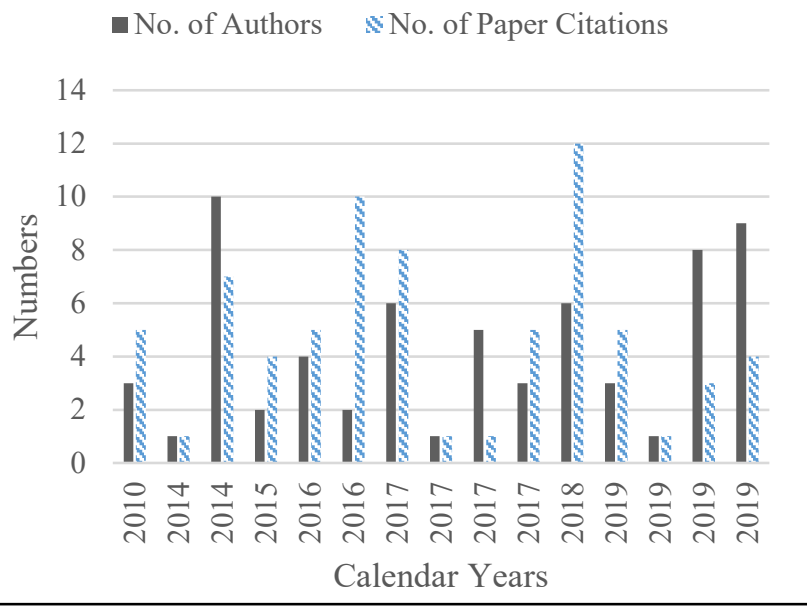

Figure 4: Number of authors versus their citations for EDUCON papers relating to Arduino as determined on 1 November 2020

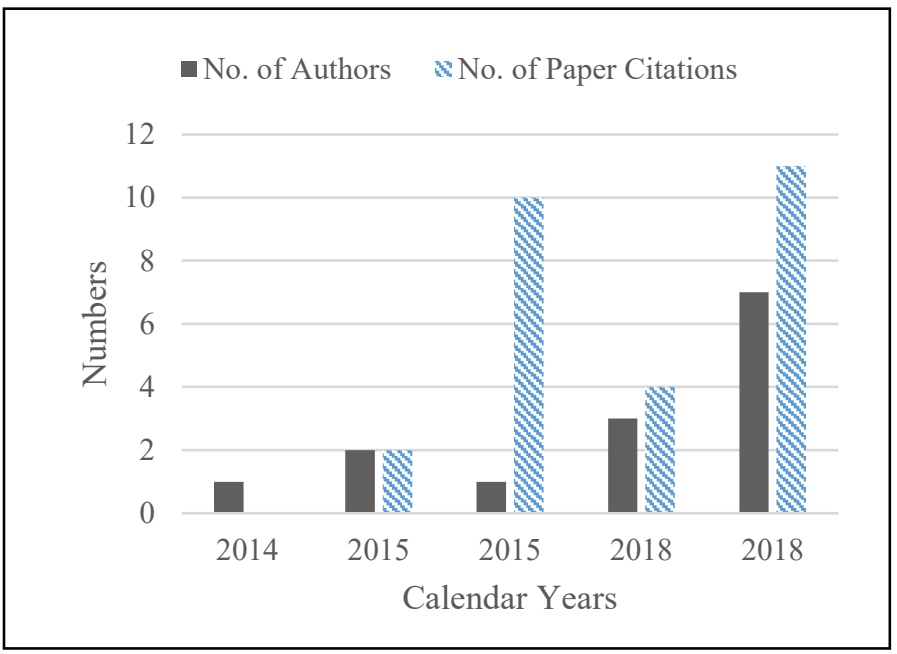

Figure 5: Number of authors versus their citations for EDUCON papers relating to the Raspberry Pi as determined on 1 November 2020

Two papers were presented in 2014 (see Figure 4), and four papers in 2019 ( $2 \times 2014$ and $4 \times 2019)$. The maximum number of authors on a paper occurred in 2014, which was ten. That specific paper applied the Arduino microcontroller to the field of Robotics at school level. Two papers that have attracted the highest citation account were presented in 2016 (it focused on the design of electronic projects in Higher Education) and in 2018 (it focused on the use of Arduino in Robotics education at school level). Two papers were presented in 2015 (see Figure 5) and another two in 2018. The paper with the highest citation count was published in 2018 and related to the field of Robotics education in Higher Education.

\subsection{FIE results}

Figure 6 contrasts the level of education, where the two microcontrollers have been applied in Engineering Education papers that were presented at FIE. Again, the Arduino dominated the discourse over the past ten years at this international conference, with the majority of papers reporting on its implementation in Higher Education. A higher number of papers have been published at FIE, compared to EDUCON. However, the trend seems to be similar between the two conferences, with the Arduino again dominating in Higher Education. Figure 7 highlights the main applications for the two microcontrollers in Engineering Education.

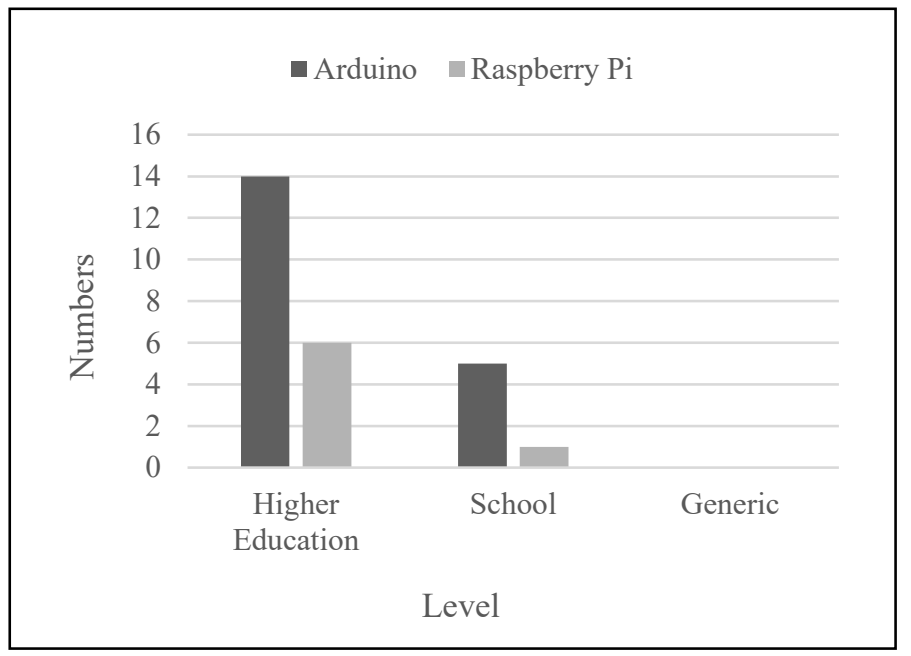

Figure 6: Level of education noted for papers presented at FIE

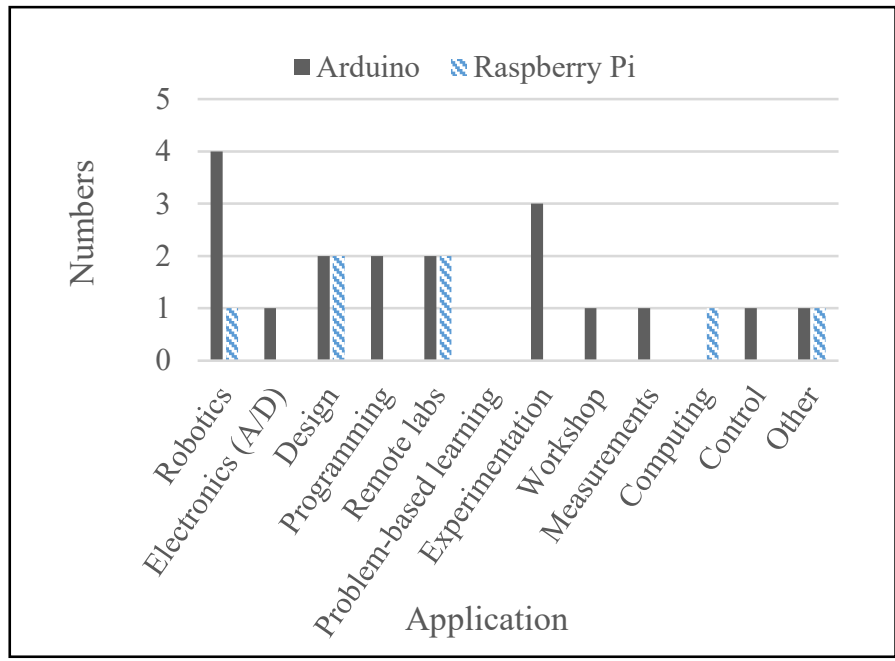

Figure 7: Applications discerned in FIE papers from 2010 onwards

Again, the field of Robotics education tops the list. However, the Arduino microcontroller has also been well applied in the field of experimentation, where two papers are focused on improving Science and Technology education at school level through laboratory experiments. The Raspberry $\mathrm{Pi}$ finds equal representation in the fields of design and remote laboratories. 
"Experimentation" relates to the use of a microcontroller to complete a basic science experiment, while "Measurements" infer the measuring and recording of different parameters, such as temperature.

Figure 8 presents the number of authors for the papers along with their citation counts. An outstanding result is the citation of 2010. That particular conference paper reported on the use of an Arduino microcontroller to help students at home to complete science and technology experiments. This research would especially be applicable to 2020, where many students were forced to stay home due to the COVID-19 pandemic. Figure 9 provides this same analysis for the Raspberry Pi.

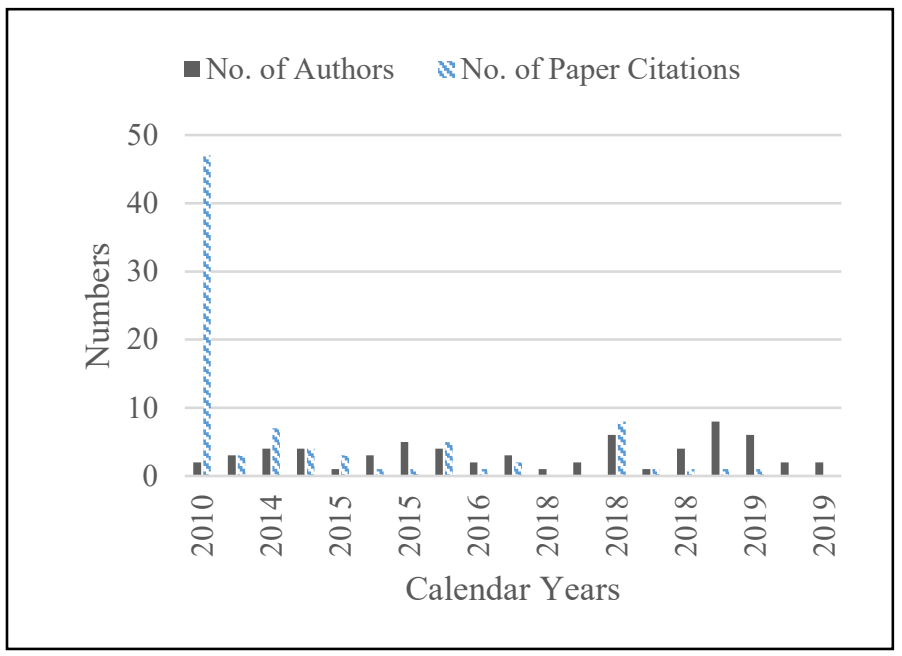

Figure 8: Number of authors versus their citations for FIE papers relating to Arduino as determined on 1 November 2020

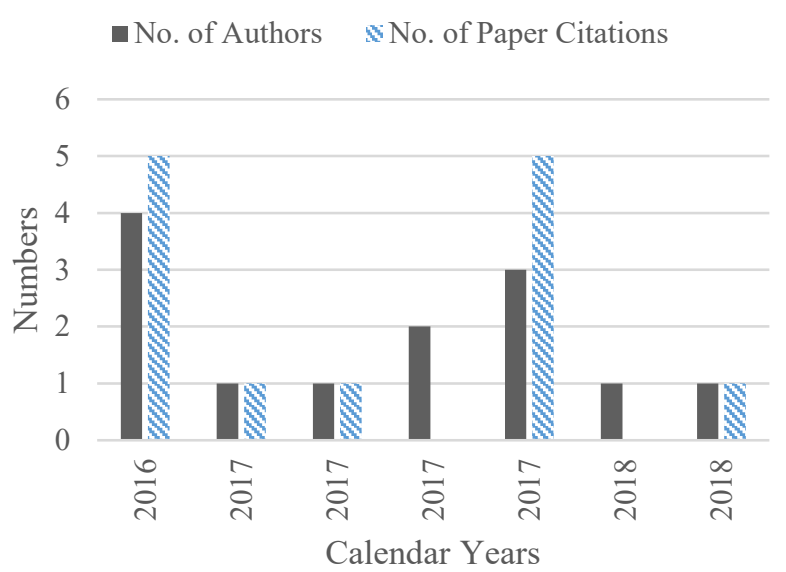

Figure 9: Number of authors versus their citations for FIE papers relating to the Raspberry Pi as determined on 1 November 2020

Four papers were presented in 2017 and another two in 2018 (see Figure 9). Two papers with the highest citation count were published in 2016 (related to the field of Robotics education in Higher Education) and in 2017 (related to remote laboratories).

Five papers were also found that reported on the use of both microcontrollers in the same course or module. All five papers reported on work done in Higher Education, where the fields of application included project-based learning, design, modelling and programming. A paper presented in 2015 has a current citation count of 29 , and reported on the use of a range of microcontrollers that were being used in a number of courses relating to project-based learning. Another paper presented in 2016 has a current citation count of 26 , and reported on the use of multiple microcontrollers in design-based learning.

\subsection{TALE results}

Figure 10 contrasts the level of education, where the two microcontrollers have been applied in Engineering Education papers that were presented at TALE. Figure 11 shows the main applications for the two microcontrollers in Engineering Education, which include Robotics education, Design and Control.

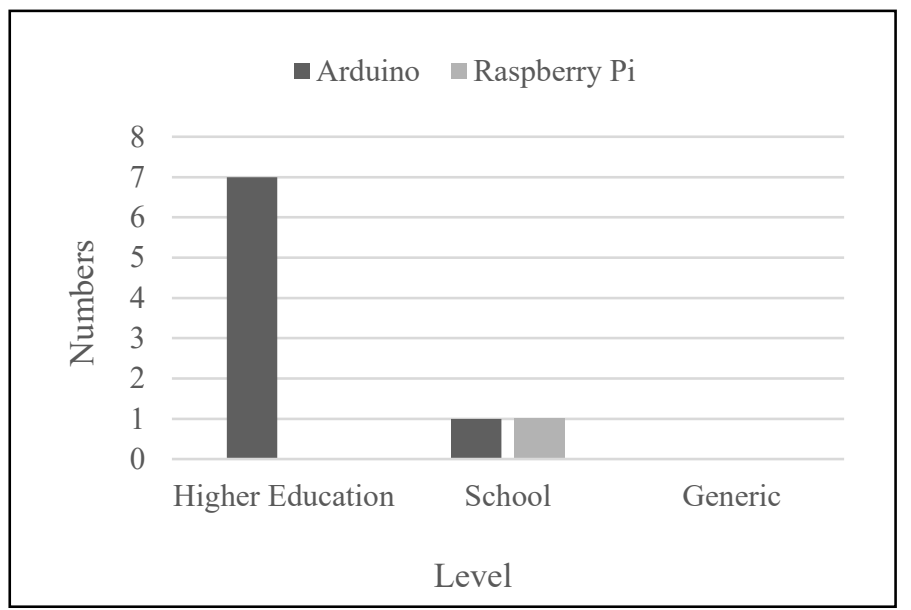

Figure 10: Level of education noted for papers presented at TALE

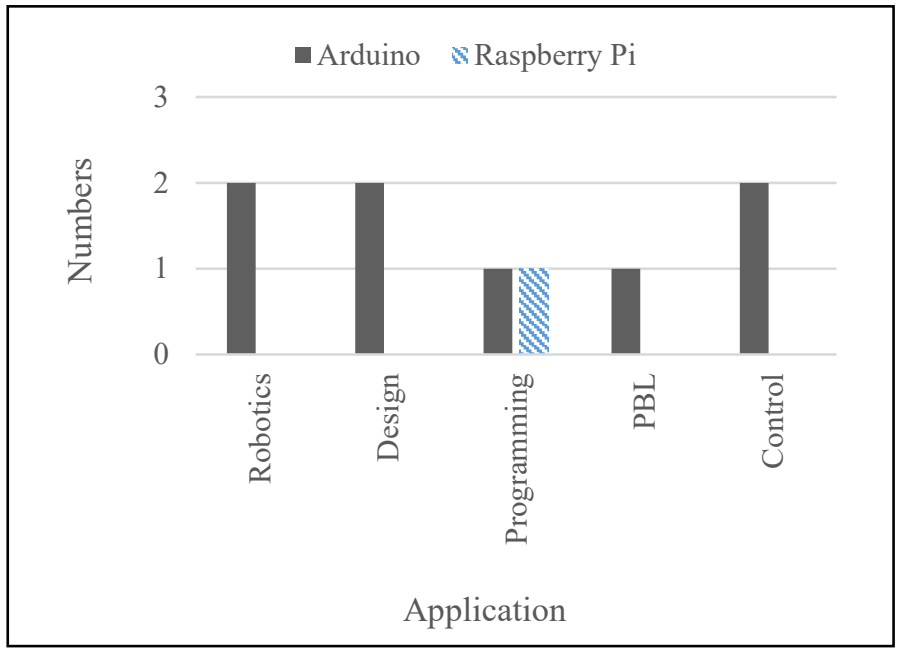

Figure 11: Applications discerned in TALE papers from 2010 onwards

Again, the use of Arduino has been well reported on in Higher Education (see Figure 10), with only two papers dedicated to this at school level for both the Arduino and Raspberry Pi. Nine papers have reported on the use of the Arduino or the Raspberry Pi over the past eight years of the TALE conference that was first held in 2012.

Figure 12 presents the number of authors for the papers along with their citation counts. Two papers were presented in 2014 and 
three in 2018. One paper presented in 2014 has a current citation count of 9, and relates to project-based learning in Higher Education. Another paper presented in 2016 currently has an equal citation count, and relates to the use of Arduino in the field of Programming for freshmen Engineering students.

Only one paper relating to the use of the Raspberry Pi in the field of Programming at school level was found. Six authors contributed to this paper that was presented in 2019, and which has no citation count as yet. Table 1 contrasts the key results between the three international conferences.

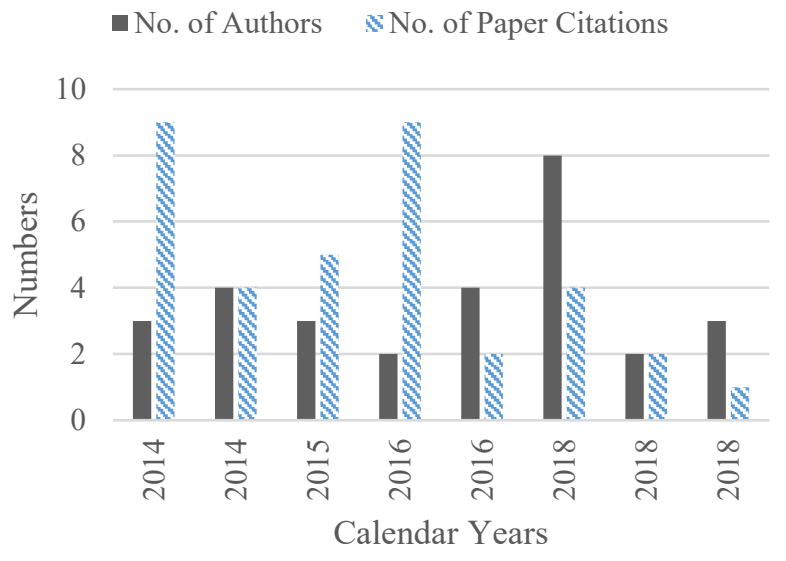

Figure 12: Number of authors versus their citations for TALE papers relating to the Arduino as determined on 1 November 2020

Table 1: Key results

\begin{tabular}{|l|c|c|c|c|c|c|}
\hline Conference & \multicolumn{2}{|c|}{ EDUCON } & \multicolumn{2}{c|}{ FIE } & \multicolumn{2}{c|}{ TALE } \\
\hline Microcontroller & Arduino & $\begin{array}{c}\text { Rasp- } \\
\text { berry Pi }\end{array}$ & Arduino & $\begin{array}{c}\text { Rasp- } \\
\text { berry Pi }\end{array}$ & Arduino & $\begin{array}{c}\text { Rasp- } \\
\text { berry Pi }\end{array}$ \\
\hline $\begin{array}{l}\text { Dominant } \\
\text { application }\end{array}$ & Robotics & $\begin{array}{l}\text { Remote } \\
\text { labs }\end{array}$ & Robotics & $\begin{array}{l}\text { Remote } \\
\text { labs }\end{array}$ & Robotics & $\begin{array}{l}\text { Program- } \\
\text { ming }\end{array}$ \\
\hline No. Papers & 15 & 5 & 19 & 7 & 8 & 1 \\
\hline $\begin{array}{l}\text { Max. No. } \\
\text { Authors on a } \\
\text { paper }\end{array}$ & 10 & 7 & 8 & 4 & 8 & 6 \\
\hline Ave. Authors & 4,3 & 2,8 & 3,3 & 1,9 & 3,6 & 6,0 \\
\hline Ave. Citations & 4,8 & 5,4 & 4,5 & 1,9 & 4,5 & 0,0 \\
\hline $\begin{array}{l}\text { Dominant } \\
\text { microcontroller }\end{array}$ & 3,0 & & 2,7 & & 8,0 & \\
\hline
\end{tabular}

FIE has a higher number of papers $(19+7=26)$ than EDUCON or TALE. However, the ratio between papers related to the Arduino and to the Raspberry Pi is very similar, being 3:1 for EDUCON and 2.7:1 for FIE. TALE has a much higher ratio, being $8: 1$. All three conferences had papers with multiple authors, while the average citation count is the highest for EDUCON (4.8 and 5.4 respectively).

\section{Possible difficulties in implementing microcontroller education at school/college/university level}

Based on the results, it can be seen that more papers have reported on the use of microcontrollers in Higher Education as opposed to school level. This may be due to a number of difficulties or challenges that are experienced at school level.

Firstly, it has been reported that schools have limited funding and resources [18] that would impact on the purchase of different technologies. Partnering with an institution of Higher Education could overcome this challenge, as many universities are mandated to engage in community development where they should make use of their resources to empower and uplift their communities.

Secondly, limited online resources to help learners or students to further their engagement with specific types of technology were noted [19]. Opting for open source software that is freely available to the public, and especially when it comes to programming that is required with microcontrollers, can help institutions or schools to decide on which option they wish to take. Both the Arduino and Raspberry Pi feature open source software. However, the Arduino is aimed at quick programming and circuit prototyping, while the Raspberry Pi acts as a learning tool for computer programming. The Arduino consumes less power than a Raspberry Pi [20], and is a cheaper board that also supports PWM and analog signals [21].

Thirdly, teaching programming is a challenge since the failure and dropout rate can be high in introductory programming courses [22]. Both teachers and learners could struggle to learn a new programming language. However, this can also be mitigated when numerous online resources and programming examples are available from which to learn. Partnering with an institution of Higher Education can also help in this regard, as academics proficient in programming can then volunteer their time to engage with learners at their schools.

\section{Opportunities for further application in Engineering Education}

Based on the EDUCON results, it can be forecasted that this international conference may see more papers in the future dedicated to using the Arduino microcontroller in Robotics education at school level. A rise in conference papers relating to its application in design-based modules may also be evident in the future. As regards the Raspberry $\mathrm{Pi}$, more remote laboratories can be set up to help students complete practical experiments from their own home. However, further applications can be recommend with regard to the Arduino that can be presented at future conferences.

One of the past papers at FIE reported on the use of Arduino in the field of Measurements [23], in terms of educating students about remote environmental monitoring (e.g. temperature and humidity). However, the field of Energy Monitoring is also growing rapidly, as more countries seek to invest in renewable energy. Institutions should seek to incorporate energy monitoring techniques into their curriculum so as to better prepare graduates for this specific industry. An example of such a technique can relate to the use of an innovative jig to stimulate awareness among Engineering students about the principle of operation of solar panels. An Arduino can be used as part of that jig to help students visualize the results of their experiments on a personal computer.

A second application relates to the remote control of electronic or mechanical equipment. The advent of the Fourth Industrial revolution has enabled the rollout of many different sensors that 
can now communicate with each other as part of the Internet of Things. One such application can focus on the remote control of garden plantation pumps using Arduino and mobile communications. Real-time monitoring of specific environmental conditions can help both academics and students to implement similar systems for other applications, such as an aquaponics system.

A third application relates to personal security. Globally, a drive exists to create awareness of gender-based violence and to empower communities to take a stand against domestic violence. Devices can be developed using microcontroller technology that can generate messages to a mobile number of a relative stipulating a victim's location and relevant surrounding information. This type of application may help students to not only think of engineering-related problems, but to also become aware of social problems that could be mitigated by the use of microcontroller technology.

A fourth application relates to workshops for academic staff. A workshop was reported on in a conference paper presented at FIE in 2019. This workshop was presented to school learners in an effort to stimulate awareness of engineering design principles [24]. Similar workshops could be designed to help promote academic development among lecturers at colleges or teachers in schools. This can form part of lifelong learning and enable individuals to remain registered with international bodies as part of their continuous professional development. An example of such a workshop can relate to helping lecturers from a technical and vocational college to improve their technical and programming skills by using the Arduino platform.

\section{Conclusions}

The purpose of this article was to analyze the application of two main microcontrollers in Engineering Education by reviewing what has been published over the past ten years at three international IEEE conferences that focus primarily on Engineering Education. Results indicate that EDUCON dominated the field of microcontroller education from 2013 to 2016, while more papers were dedicated to this topic being presented at the FIE series of conferences from 2017 to 2019.

Over the past ten years, 26 conference papers were presented at FIE relating to the Arduino and Raspberry Pi. Twenty conference papers were presented at EDUCON, while nine papers were presented at TALE. The main application of these microcontrollers has been in the field of Robotics, with general electronics and design-based learning following suit. At least eleven papers focusing on the use of these microcontrollers at school level were found. Overall, the Arduino outranks the Raspberry Pi by almost $4: 1$, with the most cited papers relating to Robotics education, to helping students at home to complete science and technology experiments, and to programming.

Further applications can extend to energy monitoring and academic development workshops. The importance of energy monitoring has increased with a global drive to install more renewable energy systems in the world. Continuous professional development is also of key importance, as professionals seek to maintain their registration with official Engineering bodies around the world.

The future of using microcontrollers in Engineering Education is indeed bright, as more academics are seeking to promote student engagement by fusing theory and practice. Only time will tell to what heights academics will rise in their innovative use of these unique microcontrollers, as future analysis will reveal further trends and opportunities in this regard.

\section{Conflict of interest}

The authors declare no conflict of interest.

\section{References}

[1] N. Kamat, E. Wu, A. Nandi, "TrendQuery: a system for interactive exploration of trends," in Proceedings of the Workshop on Human-In-theLoop Data Analytics, 1-4, 2016. doi.org/10.1145/2939502.2939514.

[2] D. E. Bolanakis, A. K. Rachioti, E. Glavas, "Nowadays trends in microcontroller education: Do we educate engineers or electronic hobbyists? Recommendation on a multi-platform method and system for lab training activities," in 2017 IEEE Global Engineering Education Conference (EDUCON), 73-77, 2017. doi.org/10.1109/EDUCON.2017.7942826.

[3] A. J. Swart, "Citation Analysis of Master Dissertations at the Central University of Technology, South Africa," AJLAIS, African Journal of Library, Archives and Information Sciences, 29(2), 115-129, 2019. DOI not available.

[4] S. Van Herck, A. M. Fiscarelli, "Mind the Gap Gender and Computer Science Conferences," in IFIP International Conference on Human Choice and Computers, 232-249, 2018.

[5] P. Sebo, "General internal medicine and family medicine journals: Comparative study of published articles using bibliometric data," Medicine, 99(24), 1-6, 2020. doi.org/10.1097/MD.0000000000020586.

[6] F. H. Siddig, "Designing and Implementing a Model for a Microcontroller Controlled Pick and Place," Masters in Engineering, Sudan University of Science and Technology, 2014.

[7] A. Busari Sherif, F. Dunmoye Abibat, F. Akingbade Kayode, "Development of Arduino-based Data Acquisition System for Environmental Monitoring using Zigbee Communication Protocol," APTIKOM Journal on Computer Science and Information Technologies, 1(3), 109-118, 2016. doi.org/10.34306/csit.v1i3.56.

[8] D. R. da S. Medeiros, M. F. Torquato, M. A. Fernandes, "Embedded genetic algorithm for low-power, low-cost, and low-size-memory devices," Engineering Reports, 2(9), 12231, 2020. doi.org/10.1002/eng2.12231.

[9] O. H. Graven, J. Bjørk, "The use of an Arduino pocket lab to increase motivation in Electrical engineering students for programming," in 2016 IEEE International Conference on Teaching, Assessment, and Learning for Engineering (TALE), 239-243, 2016. doi.org/10.1109/TALE.2016.7851800.

[10] W. Yu, O. Farook, J. P. Agrawal, A. Ahmed, "Board\# 63: Teaching Microcontrollers with Emphasis on Control Applications in the Undergraduate Engineering Technology Program," in 2017 ASEE Annual Conference \& Exposition2017. doi.org/10.18260/1-2--27895.

[11] G. Spoettl, V. Tūtlys, "Education and Training for the Fourth Industrial Revolution," Jurnal Pendidikan Teknologi dan Kejuruan, 26(1), 1-6, 2020. doi.org/10.21831/jptk.v26i1.29848.

[12] J. Vega, J. M. Cañas, "PyBoKids: an innovative python-based educational framework using real and simulated arduino robots," Electronics, 8(8), 899, 2019. doi.org/10.3390/electronics8080899.

[13] V. R. Paragarino, I. F. Silveira, M. Llamas-Nistal, "Open educational resources: A brief vision from IEEE topics," in 2018 IEEE Global Engineering Education Conference (EDUCON), 2076-2081, 2018. doi.org/10.1109/EDUCON.2018.8363495.

[14] J. A. Ariza, "A proposal for teaching programming languages through open hardware tools," in 2016 IEEE 8th International conference on engineering education (ICEED), 202-207, 2016. doi.org/10.1109/ICEED.2016.7856072.

[15] F. E. A. Batista, G. S. Junior, I. F. Oliveira, "Precariousness, flexibility, and labor relations in the Fashion Industry," Research, Society and Development, 10(1), e11510110841-e11510110841, 2021.

[16] Y. Xie, L. Ji, B. Zhang, G. Huang, "Evolution of the scientific literature on input-output analysis: A bibliometric analysis of 1990-2017," Sustainability, 10(9), 3135, 2018. doi.org/10.3390/su10093135. 
[17] J. M. Levitt, M. Thelwall, "Long term productivity and collaboration in information science," Scientometrics, 108(3), 1103-1117, 2016. doi.org/10.1007/s11192-016-2061-8.

[18] S. A. Nadira, L. Shixiang, X. Chen, "SWOT Analysis of the Management and Operation of Secondary Education System in Dhaka City of Bangladesh," International Journal of Science, Technology and Society, 8(4), 80, 2020. doi.org/10.11648/j.ijsts.20200804.11

[19] N. R. Hussein, Z. S. M Saleem, D. H. Musa, N. Ibrahim, I. A. Naqid, "Impact of COVID-19 on the medical education: experience from Kurdistan region of Iraq," Journal of Medical Education, 19(1), 1, 2020. doi.org/10.5812/jme.106889.

[20] C. A. Okigbo, A. Seeam, S. P. Guness, X. Bellekens, G. Bekaroo, V. Ramsurrun, "Low cost air quality monitoring: comparing the energy consumption of an arduino against a raspberry Pi based system," in Proceedings of the 2nd International Conference on Intelligent and Innovative Computing Applications, 1-8, 2020.

[21] E. Lemos, A. Ghoshal, A. Aspat, "Hardware Architecture and Implementation of an AI Pet Robot," International Journal of Applied Sciences and Smart Technologies, 2(2), 21-46, 2020. doi.org/10.24071/ijasst.v2i2.2792.

[22] Z. Mabni, N. Shamsudin, S. Aliman, R. A. Latif, "Factors Influencing Students' Performance in the First Computer Programming Course Taught Using Blended Learning Approach," Environment-Behaviour Proceedings Journal, 5(SI3), 181-186, 2020. doi.org/10.21834/ebpj.v5iSI3.2559.

[23] D. Călinoiu, R. Ionel, M. Lascu, A. Cioablă, "Arduino and LabVIEW in educational remote monitoring applications," in 2014 IEEE Frontiers in Education Conference (FIE) Proceedings, 1-5, 2014. doi.org/10.1109/FIE.2014.7044027.

[24] A. J. Penn, A. Baynes, "Exploring How Affinity toward Engineering Increases in Underserved Youth After Summer Physical Computing Workshop," in 2019 IEEE Frontiers in Education Conference (FIE), 1-5, 2019. doi.org/10.1109/FIE43999.2019.9028706. 